\title{
Minimizing interspecific competition by different foraging strategies in two North African desert rodents
}

\author{
Rüdiger SCHRÖPFER and Brigitte KLENNER-FRINGES
}

\begin{abstract}
Schröpfer R. and Klenner-Fringes B. 1991. Minimizing interspecific competition by different foraging strategies in two North African desert rodents. Acta theriol. 36: 109- 117.

In most deserts, rodent species are represented numerously, most of them being granivorous. Several studies deal with the question, what the mechanisms of coexistence in such rodent communities are. In this paper the hypothesis is tested, whether the two locomotion types quadrupedal running and bipedal saltation - may be responsible for the syntopic occurence of the two granivorous desert rodent species Jaculus jaculus (Linnaeus, 1758) and Gerbillus gerbillus Oliver, 1801. The behaviour analysis in a special observation laboratory has shown that the bipedal $J$. jaculus is less attached to the burrow site, covering a wide area with a wide-meshed net of locomotion pattern, and using only a small part of discovered food resources. The quadrupedal $G$. gerbillus shows a close contact to the burrow, an intensive utilization of the area round the burrow, and a food utilization of nearly $100 \%$. According to these different strategies in searching for food and food utilization the conclusion can be drawn that (1) by using a wide area $J$. jaculus always finds new food patches, and (2) that $G$. gerbillus profits by the fact, that $J$. jaculus never uses a food patch in total.
\end{abstract}

Ethology, Department Biology/Chemistry, University of Osnabrück, Barbarastrasse 11, D-4500 Osnabrïck, Germany

Key words: interspecific competition, food utilization, Jaculus jaculus, Gerbillus gerbillus

\section{Introduction}

In the mammal fauna of deserts, rodents are represented numerously. It is remarkable that several species can coexist, although most of them are granivorous. Because seeds do not accumulate all over the year, food may form the limiting factor for which the syntopic species of such a desert rodent community compete (Slobotkin et al. 1967). Such competition can be conceivable as direct interference and/or exploitative competition (Pianka 1983). The question arises, how several species of granivorous desert rodents manage to coexist. What are the mechanisms of coexistence? Brown and Libermann (1973), Brown $(1973,1975)$ suggest that differences in body size lead to the preference of different sized seeds and thereby to niche separation. Price (1978) explaines the coexistance of several species of Heteromyid rodents with the preference of different microhabitats, where differences in seed production may play an important role (Price and Reichman 1987). M'Closkey (1978) suggests that according to the species diversity seed-size and/or differences in habitat are responsible for the coexistence. Brown (1989) tested four mechanisms of coexistance in North American desert rodents: microhabitat selection, spatial and temporal variation in resource abundances, and seasonal chages in foraging efficiencies. He also deals with the question of differences in patch use as 
an indicator of habitat selection, predation risk, and competition by studying the giving up densities of seed patches (Brown 1988).

Discussing the factors that could influence the foraging behaviour of desert rodents, Reichman (1981) pointed out the possibility of high locomotory efficiency of bipedal kangaroo rats compared with quadrupedal species of the genus Perognathus. Quadrupedal and bipedal species often coexist: for example Gerbillus resp. Meriones, and Jaculus resp. Allactaga in North Africa (Petter 1961, Ranck 1968, Happold 1975), in Arabia (Harrison 1972), Pakistan (Roberts 1977), the Iran (Misonne 1975), and in the USSR (Naumov and Lobochev 1975), and Perognathus and Dipodomys in North America (Brown 1973, Smigel and Rosenzweig 1974).

Analysing the locomotion type of two allopatric jerboa species (Jaculus jaculus and $J$. orientalis; Schröpfer et al. 1985) we found that the differences in the locomotion type are responsible for different locomotion pattern in different vegetation types. In Tunisia, the bipedal Jaculus jaculus insert the names of scientists and years of description and the quadrupedal Gerbillus gerbillus are living sympatricly. Studying the locomotion pattern of these two granivores we came to the question whether differences in locomotion are responsible for different foraging strategies. This could be one factor to minimize competition in these two species.

\section{Material and methods}

The two species, observed in this laboratory study, are Jaculus jaculus $(J . j$.$) (Dipodidae, Dipodinae) and$ Gerbillus gerbillus (G. g.) (Cricetidae, Gerbillinae). The individuals ( 3 J. j., 4 G. g.) were caught in a sandy area with very sparse vegetation (covering less than $2 \%$ ) near the Chott el Djerid westward from Tozeur, Tunisia, where both species live syntopical.

The animals were observed by a video monitoring-system in a special observation room of $9 \mathrm{~m}^{2}$, filled with sand (15 cm deep). An artificial borrow was burried in the sand, leaving only the entrance visible. Five flat vessels ( $20 \mathrm{~cm}$ in diameter, $4 \mathrm{~cm}$ deep) were spead out regularly and covered with sand so that they were invisible. Each vessel contained 100 unpeeled sunflower seeds, mixed into the sand. (The animals got sunflower seeds in their daily diet and prefered them to other seeds). The temperature in the observation room was about $18^{\circ} \mathrm{C}$. During "nighttime" hours a blue lamp provided 10 lux of illumination. In "daylight", neon lamps provided 170 lux.

All individuals were active only in the dark. We placed each animal in the observation room for 64 hours. Each animal was placed in the room 4 hours before light on and 16 hours to get accustomed to the room. None of the animals had prior experience with the observation room. Then, each individual was observed for two nights running (LD 12:12).

The analysis of the video-tapes (taken at normal speed) was made at a monitor with a screen foil overlay showing burrow location and food patches. Thus the observer was able to record the phase of activity (PA: the period between first leaving the burrow and last returning to it during one night), time of activity (TA: the time an animal really spent outside the burrow during one night), trips to the burrow, run lengths between two stops, locomotion pattern, ultilization of the offered food (hoarding, eating), and mobility (defined as number of site changes per hour of TA). We counted as a site change any movement by an animal which carried it from one field of the screen foil to another. The run lenghts of each site change were measured in units of $20 \mathrm{~cm}$, corresponding to the fields of the screen foil. A "stay" means that the animals stopped running and started searching for food, grooming, etc. for five or more seconds. For statistical comparisons the Mann-Whitney- $U$-Test was used. 


\section{Results}

\section{Activity and constraint to the burrow}

The phase of activity (PA), time of activity (TA) and percentage PA spent active were significantly longer for $G . g$. than for $J . j$. (Table 1). As $J$. $j$. never hoarded seeds, in the following comparison the trips to the burrow made by $G . g$. when hoarding seeds, were not counted. Nevertheless, $G . g$. returned to its burrow significantly more frequently than did $J . j$. (Table 1).

There was a lot of variance in the time, the animals spent in the burrow during one PA (J. $j .: \min 0.35 \mathrm{~h}, \max 4.35 \mathrm{~h} ; G . g .: \min 0.09 \mathrm{~h}, \max 4.48 \mathrm{~h}$ ). According to this there was no significant difference between the two species in the absolute time per PA spent in the burrow. But there was a difference in percentage of PA spent in the burrow: $J$. $j$. spent a significantly

Table 1. Phase of activity (PA) and time of activity (TA) (in hours), number of trips to the burrow, time spent in the burrow during the phase of activity (median, mean absolute deviation, number of nights, minimum, maximum).

\begin{tabular}{|c|c|c|c|c|}
\hline Events & J. jaculus & G. gerbillus & $p$ & $U$ \\
\hline PA & $\begin{array}{l}7.52 \\
0.66 \\
6 \\
7.12 \\
10.32\end{array}$ & $\begin{array}{c}11.05 \\
0.47 \\
8 \\
10.37 \\
11.60\end{array}$ & $\begin{array}{c}J . j .<G . g . \\
0.001\end{array}$ & 0 \\
\hline TA & $\begin{array}{l}6.64 \\
1.20 \\
6 \\
3.26 \\
7.09\end{array}$ & $\begin{array}{l}10.42 \\
0.75 \\
7 \\
6.74 \\
11.11\end{array}$ & $\begin{array}{c}J . j .<G . g . \\
0.005\end{array}$ & 3 \\
\hline $\begin{array}{l}\text { Percentage of PA spent } \\
\text { active }(\mathrm{TA} / \mathrm{PA} \times 100 \%)\end{array}$ & $\begin{array}{c}76.62 \\
16.42 \\
6 \\
42.78 \\
95.23\end{array}$ & $\begin{array}{c}96.71 \\
7.31 \\
7 \\
60.08 \\
99.15\end{array}$ & $\begin{array}{c}J . j .<G . g . \\
0.025\end{array}$ & 5 \\
\hline $\begin{array}{l}\text { Number of trips to } \\
\text { the burrow per PA }\end{array}$ & $\begin{array}{c}11.50 \\
6.00 \\
6 \\
6.00 \\
22.00\end{array}$ & $\begin{array}{c}37.00 \\
8.29 \\
7 \\
27.00 \\
56.00\end{array}$ & $\begin{array}{c}J . j .<G . g . \\
0.001\end{array}$ & 0 \\
\hline $\begin{array}{l}\text { Percentage of time spent } \\
\text { in the burrow during PA }\end{array}$ & $\begin{array}{c}23.38 \\
16.42 \\
6 \\
4.77 \\
57.22\end{array}$ & $\begin{array}{l}3.29 \\
6.99 \\
7 \\
0.85 \\
39.92\end{array}$ & $\begin{array}{c}J . j .>G . g . \\
0.025\end{array}$ & 5 \\
\hline
\end{tabular}


higher percentage of the PA in the burrow than did G. g. (Table 1). In the mean G. g. returned three times more often into the burrow than did $J$. $j$. In addition to the fact that $G$. $g$. used the burrow more frequently for storing seeds (see "Food utilization"), the large amount of time spent on fields near the entrance of the burrow and the high intensity of digging near the burrow may give a greater constraint to the burrow in $G . g$. (Table 2).

Table 2. Constrain to the burrow.

\begin{tabular}{lcc}
\hline Events & J.jaculus & G. gerbillus \\
\hline $\begin{array}{l}\text { Digging events near the burrow } \\
\text { Number of observations on the }\end{array}$ & 0 & 1881 \\
fields of the entrances to the burrow & 557 & 3279 \\
\hline
\end{tabular}

\section{Locomotion pattern and space utilization}

Although there was great variability in both species, the $U$-test showed that $G . g$. had a significantly higher rate of site changes than $J$. $j$. (Table 3 ). The number of run lengths (corresponding to the number of site changes, was in total for J. j. 6407 and for G. g. 30901. The greatest distance, covered by a site change in $J$. $j$., was $23 \mathrm{~m}$; for $G$. g. it was $5 \mathrm{~m}$. In both species, extremly short distances $(20 \mathrm{~cm})$ formed the majority of runs $(J . j .: 60.31 \%$; G. $g .: 63.9 \%)$. The species differed in their frequency of long-distance runs. The percentage

Table 3. Mobility (number of site changes per hour of TA) and run lengths (median, mean absolute deviation, number of nights, minimum, maximum).

\begin{tabular}{|c|c|c|c|c|}
\hline Events & J. jaculus & G. gerbillus & $p$ & $\mathrm{U}$ \\
\hline \multirow[t]{5}{*}{ Mobility } & 162.00 & 423.40 & J. j. < G. g. & 3 \\
\hline & 87.13 & 57.08 & 0.01 & \\
\hline & 6 & 8 & & \\
\hline & 43.08 & 234.05 & & \\
\hline & 291.88 & 606.86 & & \\
\hline \multirow[t]{5}{*}{ Distances $\leq 20 \mathrm{~cm}$ (in \%) } & 51.00 & 65.40 & J. J. = G. g. & 17 \\
\hline & 15.17 & 5.89 & 0.5 & \\
\hline & 6 & 8 & & \\
\hline & 27.93 & 48.69 & & \\
\hline & 82.99 & 75.43 & & \\
\hline \multirow[t]{5}{*}{ Distances $\geq 1 \mathrm{~m}$ (in \%) } & 28.05 & 12.17 & J. j. > G. g. & 8 \\
\hline & 7.89 & 3.46 & 0.05 & \\
\hline & 6 & 8 & & \\
\hline & 6.41 & 4.55 & & \\
\hline & 33.88 & 17.35 & & \\
\hline
\end{tabular}


of distances $\geq 1 \mathrm{~m}$ was significantly higher in $J . j$. (Table 3 ). The relation of distances $>2 \mathrm{~m}:<2 \mathrm{~m}$ was $1: 7.3$ for $J . j$. and $1: 46$ for $G$. g. This means that $J . j$. ran distances longer than $2 \mathrm{~m}$ six times more frequently than $\operatorname{did} G . g$.
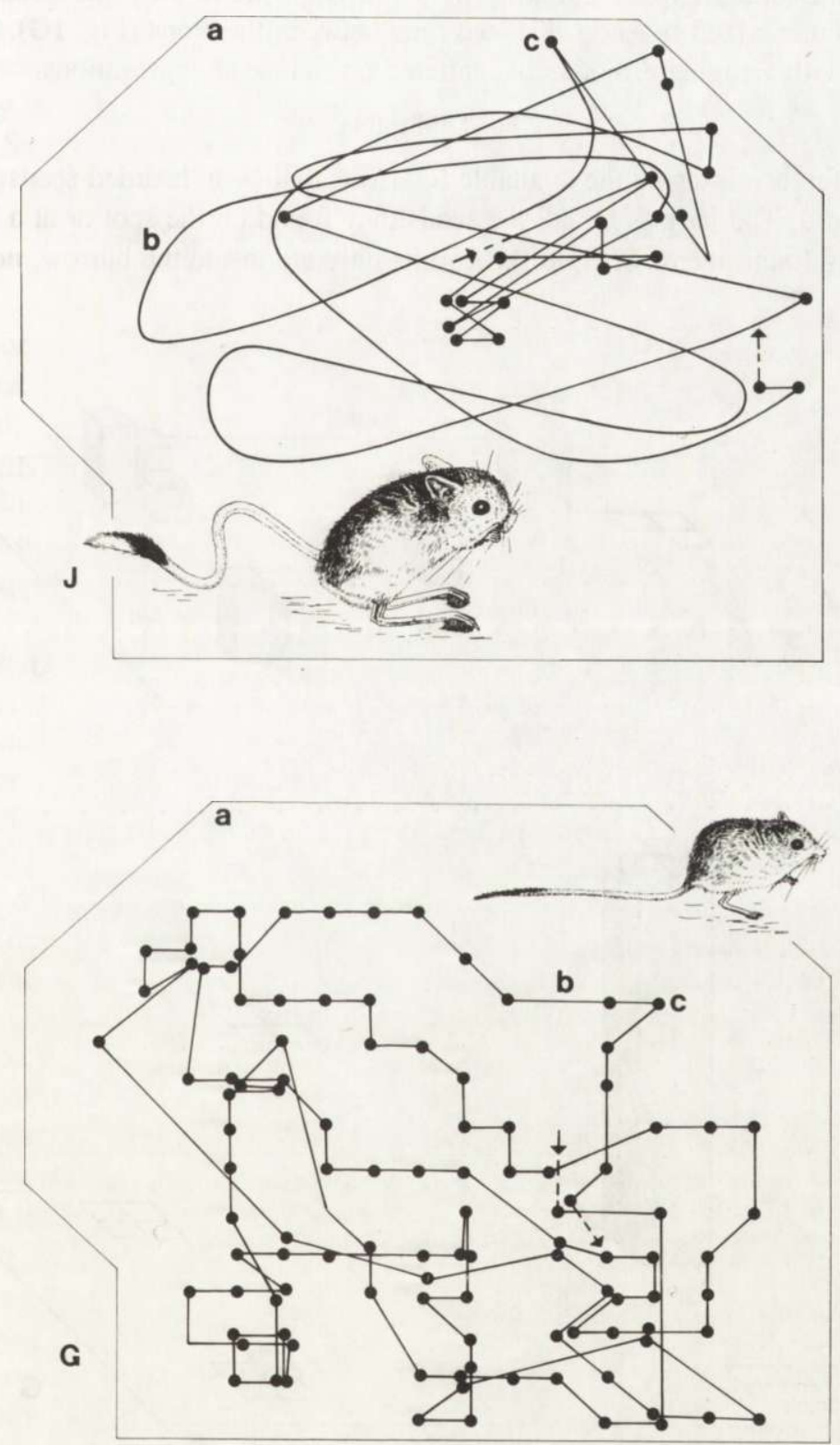

Fig. 1. Locomotion pattern of J.jaculus (J) and G. gerbillus (G):

(a) limitation of sand area, (b) distance covered, (c) searching bout. 
The corresponding locomotion pattern of $J . j$. looked like a widemeshed net: small "knots", covered with short distance runs, were connected with long distance runs (Fig. 1J). The resulting use of the area corresponds to an accumulated distribution of stops, where - among other things - the animals were searching for food. Opposite to this, the locomotion pattern of $G$. g. was characterized by short distance runs between the stops (Fig. 1G). The area was used regularly with foraging effeorts concentrated on rich seed aggregations.

\section{Food utilization}

A major difference in using the available food was that $G . g$. hoarded seeds in the burrow and $J . j$. never did. The jerboas ate all the seeds they found on the spot or at a little distance from where they found them, whereas the gerbils only ate inside the burrow, never outside.
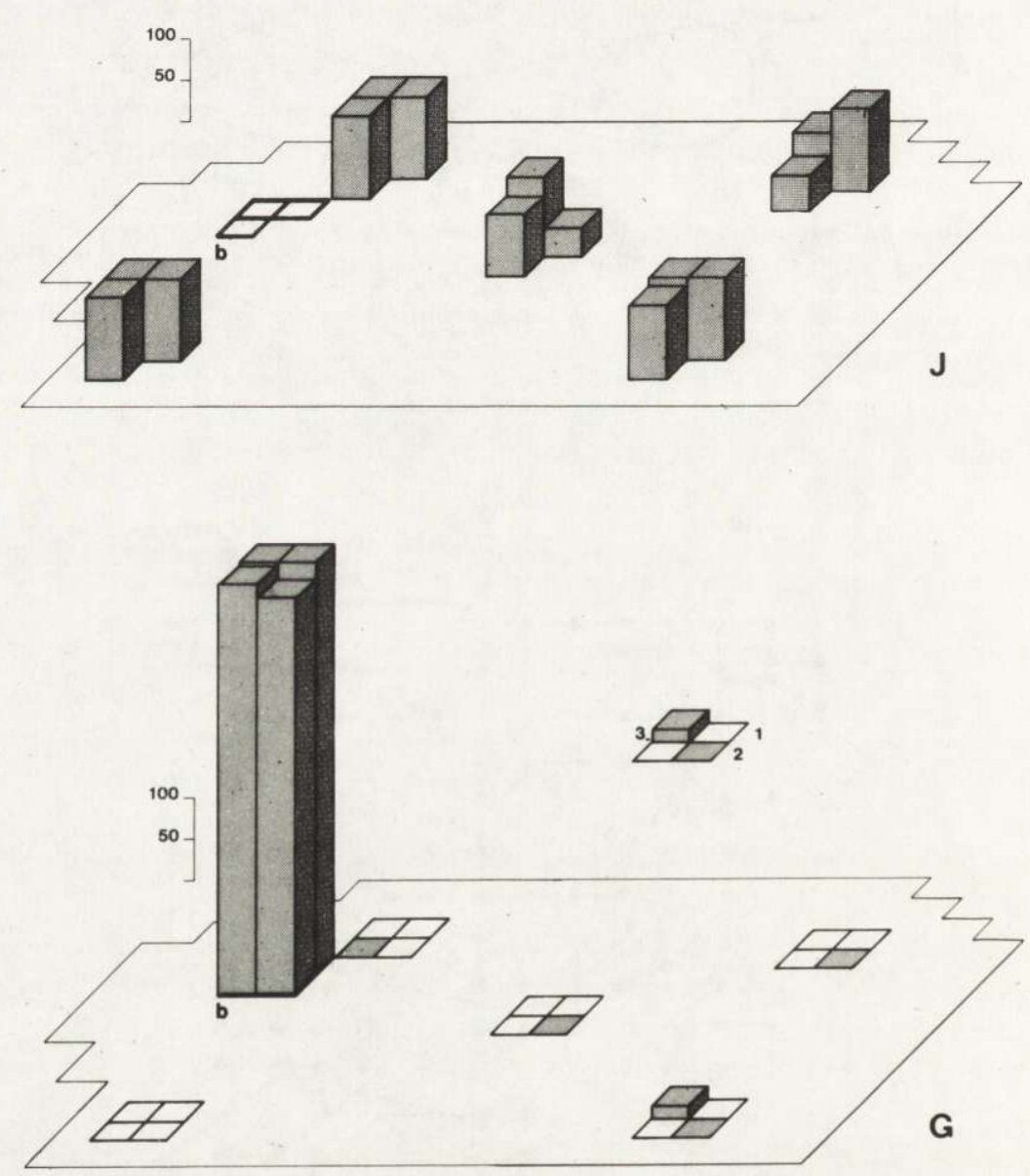

Fig. 2. Remains of seeds per feeding site resp. seed stock in the burrow for three jerboas (J) and four gerbils (G) at the end of the phase of observation: (b) burrow, (1) no seeds, (2) $<4$ seeds, (3) $4>$ seeds (see scale). 
The individuals of $J . j$. used the seed aggregations in a very different way from $G . g$. (Fig. 2J) and sometimes only very few seeds were found. In 8 cases out of 15 no seeds were eaten. Only 6 to $19 \%$ of the offered food was harvested. In contrast $G$. g. used 96 to $100 \%$ of the seeds by hoarding them in the burrow, and all seed patches were used regularly (Fig. 2G). The seed patches were not cleared at a single stretch, but during several phases of hoarding, often with great temporal separation.

The frequency of return to a seed patch in a night was lower for $J . j .(\bar{x}=7.5)$ than for G. g. $(\overline{\mathrm{x}}=34.4)$. So the probability of visiting a seed patch as much as $G . g .(34.4$ times) was nearly zero for $J . j$. (Poisson distribution).

\section{Discussion}

The comparison of the two granivorous species J. jaculus and G. gerbillus shows two very different strategies:

J. j. - bipedal; long distance runner, covering a great home range (Petter 1961) with a locomotion pattern like a wide-meshed net: intensivly searched "knots" where we find shortdistance runs connected with long-distance runs; never caching seeds but always harvesting at new more or less rich food patches.

G. g. - quadrupedal; short-distance runner, carefully searching for seeds in a relativly small area (Wandeler 1966, Happold 1975); exploiting the food patches up to the bottom, hoarding all the seeds, it finds, in the burrow.

In North America, Thompson (1982) found similar differences in the locomotion pattern of bipedal (Dipodomys deserti, D. merriami) and quadrupedal (Perognathus longimembris) species. The latter exploites a small area including one or two perennial shrubs, searching intensivly for seeds and running short distances. The kangaroo rats show a locomotion pattern similar to $J$. jaculus: running short distances while searching carefully for seeds under bushes and running long distances while crossing the open area (see also Bowers 1982).

It seems as if the locomotion pattern of these species depend on the presence of perennial shrubs, whereas the two African species we studied, show the same pattern but independent from vegetation. This may be a hind that for $J . j$. and $G$. g. the dispersion pattern of chosen foraging sites is perhaps determined by the locomotion pattern of these species.

It-is striking that both forms of locomotion (bipedal and quadrupedal) are found syntopically in most desert rodent communities. Within one form of locomotion, body size may play an important role (Brown 1975) and the null-hypothesis can be tried (Bowers and Brown 1982) (compare also to the coexistence of different sized species of the family Dipodidae in the USSR; Heptner et al. 1966). In the case of $J . j$. and G. g. the intensity of exploitation seems to be connected with the locomotion type: in our study the quadrupedal $G$. g. used the seed clumps with a percentage of nearly 100 whereas the bipedal $J . j$. used only a very small part. $G$. $g$. often returned to the same foraging site, $J$. $j$. did not.

There is a main difference between the foraging behaviour of the North American genus Dipodomys and the Asian and African subfamilies Dipodinae and Allactinae. Concerning the lack of the "storing habit" in the Dipodinae and Allactinae compare Naumov et al. 1975. The comparison of $J . j$. and $G . g$. may be an example for the connection of different locomotion 
types and different foraging strategies we find in African and Asian desert rodents. This also may play an important role in minimizing predation risk. For example $J$. $j$. closes its burrow carefully when leaving it. Running long distances and using a large home range can mean that it might be impossible to flee from predators into the burrow. But there must be other mechanisms of minimizing predation risk. G. g., using a small area as a home range, returns in case of danger into the burrow.

The strategy of $G . g$. aims at catching as much food as possible whereas $J$. $j$. only takes the rate of seeds that is necessary to support the daily energy requirements. This might be more economical than running long distances back to the burrow to hoard few seeds $(J . j$. has no cheek-pouches like the kangaroo rats). $J . j$. needs a PA and TA shorter than $G$. $g$. This can also be a contribution to minimize predation risk.

For $J . j$. never depletes seed patches, it is no competitor for $G . g$. and perhaps other quadrupedal species. And as $J$. $j$. searches a large area in a special way (see locomotion pattern), it may always find enough seeds. Perhaps this could explain the fact that both, J. j. and G. g., are able to tolerate each other as Happold (1975) observed in the deserts of the Sudan.

It seems that the composition of syntopic rodent species due to different locomotion types is not restricted to desert biotopes. Such a species combination can also be found in the Sylvaea region, for example in the deciduous woods of Middle Europe (Schröpfer 1989, 1990). Here the combination of species of the quadrupedal hopping type (Apodemus) and species that belong to the quadrupedal running type (Clethrionomys) is found. Because such a combination of species occurs in biotops with sparse vegetation as well as in such with rich vegetation, it seems to be a principle that makes possible the coexistence of closely related species in the same habitat.

\section{References}

Bowers M. A. 1982. Foraging behaviour of heteromyid rodents: field evidence of resource partitioning. J. Mammal. 63: $361-367$.

Bowers M. A. and Brown J. H. 1982. Body size and coexistence in desert rodents: chance or community structure? Ecology 63: $391-400$.

Brown J. H. 1973. Species diversity of seed-eating desert rodents in sand dune habitats. Ecology 54: 775 - 787.

Brown J. H. 1975. Geographical ecology of desert rodents. [In: Ecology and evolution of communities. M. L. Cody and J. M. Diamond, eds]. The Belknap Press of Harvard University Press, Massachusetts.

Brown J. H. and Liebermann G. A. 1973. Resource utilization and coexistence of seed-eating desert rodents in sand dune habitats. Ecology 54: $788-797$.

Brown J. S. 1988. Patch use as an indicator of habitat preference, predation risk, and competition. Behav. Ecol. Sociobiol. 22: $37-47$.

Brown J. S. 1989. Desert rodent community structure: a test of four mechanisms of coexistence. Ecological Monographs 59: $1-20$.

Happold D. C. D. 1975. The ecology of rodents in the northern Sudan. [In: Rodents in desert environment. I. Prakash and P. K. Ghosh, eds]. Junk Publishers, The Hague: $15-45$.

Harrison D. L. 1972. The mammals of Arabia. Lagomorpha, Rodentia. Enest-Benu Ltd., 3: $385-670+$ XVII. London.

Heptner W. G., Morosova L. G. and Zalkin W. J. 1965. Die Säugetiere in der Schutzwaldzone. Berlin.

M'Closkey R. T. 1978. Niche separation and assembly in four species of Sonoran Desert rodents. Amer. Naturalist 112: $683-694$. 
Misonne X. 1975. The rodents of the Iranian deserts. [In: Rodents in desert environment. I. Prakash and P. K. Ghosh, eds]. Junk Publishers, The Hague: $47-58$.

Naumov N. P. and Lobachev V. S. 1975. Ecology of desert rodents of the U.S.S.R. (jerboas and gerbils). [In: Rodents in desert environment. I. Prakash and P. K. Ghosh, eds]. Junk Publishers, The Hague: 465-598.

Petter F. 1961. Répartition géographique et ecologie des rongeurs désertiques (du Sahara occidental et l'Iran orintal). Mammalia 25: $1-222$.

Pianka E. R. 1983. Evolutionary ecology. Harper and Row, New York.

Price M. V. 1978. The role of microhabitat in structuring desert rodent communities. Ecology 59: 910 - 921.

Price M. V. and Reichman O. J. 1987. Distribution of seeds in Sonoran desert soils: Implications for Heteromyid rodent foraging. Ecology 68: $1797-1811$.

Ranck G. L. 1968. The rodents of Libya; taxonomy, ecology and zoogeographical relationships. Smithsonian Inst. Press, Washington DC.

Reichman O. J. 1981. Factors influencing foraging in desert rodents. [In: Foraging behavior. A. C. Kamil and T. D. Sargent, eds]. Garland STPM Press, New York, London.

Roberts T. J. The mammals of Pakistan. Tonbridge, London.

Schröpfer R. 1989. Habitatpräferenz und Struktur silvicoler Theriozönosen. Verh. 17. Jtg. Ges. f. Ökologie, Göttingen XVII, 1987: 437 - 443.

Schröpfer R. 1990. The structure of European small mammal communities. Zool. Jb. Syst. Ökol. Tiere 117: $355-367$.

Schröpfer R., Klenner-Fringes B. and Naumer E. 1985. Locomotion pattern and habitat utilization of the two jerboas Jaculus jaculus and Jaculus orientalis (Rodentia, Dipodidae). Mammalia 49: 445 - 454.

Slobodikn L. B., Smith F. E. and Hairston N. G. 1967. Regulation in terrestrial ecosystems, and the implied balance of nature. Amer. Naturalist 101: 109 - 124.

Smigel B. W. and Rosenzweig M. L. 1974. Seed selection in Dipodomys merriami and Perognathus penicillatus. Ecology 55: $329-339$.

Thompson S. D. 1982. Microhabitat utilization and foraging behavior of bipedal and quadrupedal heteromyid rodents. Ecology 63: $1303-1312$.

Wandeler A. J. 1966. Die Wirbeltiere von Hefta. Jahrb. Naturh. Museum Bern 1963-1965: 229 - 292.

Received 29 January 1990, accepted 10 July 1991. 